\title{
Capsule Endoscopy in Inflammatory Bowel Disease Type Unclassified and Indeterminate Colitis Serologically Negative
}

\author{
Sandra Lopes, MD, Pedro Figueiredo, MD, PhD, Francisco Portela, MD, Paulo Freire, MD, Nuno \\ Almeida, MD, Clotilde Lérias, MD, Hermano Gouveia, MD, and Maximino Correia Leitão, MD, PhD
}

\begin{abstract}
Background: The value of capsule endoscopy in the setting of inflammatory bowel disease type unclassified (IBDU) and indeterminate colitis (IC) remains obscure. The aim was to evaluate the clinical impact of capsule endoscopy on IBDU/IC patients with negative serology.
\end{abstract}

Methods: Eighteen patients with long-standing IBDU $(n=14)$ and IC $(n=4)$ were enrolled to undergo a capsule endoscopy and then followed prospectively. Lesions considered diagnostic of Crohn's disease (CD) were 4 or more erosions/ulcers and/or a stricture. The median follow-up time after capsule endoscopy was $32 \pm 11$ months (23-54 months).

Results: Total enteroscopy was possible in all patients. In 2 patients the examination was normal (Group 1). In 9 patients subtle findings were observed (Group 2): focal villi denudation $(n=1)$ and fewer than 4 erosions/ulcers $(n=8)$. In 7 patients, 4 or more erosions/ulcers were detected (Group 3), leading to a diagnosis of CD. However, their treatment was not reassessed on the basis of the capsule findings. Until now, a definitive diagnosis has been achieved in 2 additional patients: 1 from Group 1 (ulcerative colitis) and another patient from Group 2 (CD), who began infliximab infusions. Nine patients remained indeterminate at follow-up.

Conclusions: Although capsule endoscopy enabled the diagnosis of $\mathrm{CD}$ in 7 patients, in none of them was the clinical management changed. Moreover, a change in therapy due to a diagnosis of $\mathrm{CD}$ was made for only 1 patient, who presented nonspecific findings. Our results suggest that capsule findings are not helpful in the work-up of these patients.

(Inflamm Bowel Dis 2010;16:1663-1668)

Key Words: inflammatory bowel disease type unclassified, indeterminate colitis, long-standing disease, negative serology, capsule endoscopy

Received for publication December 13, 2009; Accepted January 11, 2010.

From the Gastroenterology Department, Coimbra University Hospital, Coimbra, Portugal.

Reprints: Sandra Lopes, MD, Serviço de Gastrenterologia, Hospitais da Universidade de Coimbra, Praceta Mota Pinto, 3000-075 Coimbra, Portugal (e-mail: sandraflopes@sapo.pt)

Copyright $\odot 2010$ Crohn's \& Colitis Foundation of America, Inc.

DOI 10.1002/ibd.21249

Published online 27 March 2010 in Wiley Online Library (wileyonlinelibrary.com).
$\mathrm{T}$ he distinction between Crohn's disease (CD) and ulcerative colitis (UC) is supported by clinical, radiological, endoscopic, and pathological information. ${ }^{1}$ Unfortunately, in $10 \%-15 \%$ of patients the distinction cannot be made easily, so that the term indeterminate colitis (IC) has been adopted in such cases. ${ }^{2}$ However, the term has been used with different definitions, leading to considerable confusion. ${ }^{3}$ Following the report of the Montreal Working Party in 2005 , it was proposed that the term indeterminate colitis should be reserved for cases in which a surgical specimen is available, while the term inflammatory bowel disease type unclassified (IBDU) should be used for patients who present divergent clinical, endoscopic, and histological features and for whom no surgical specimen is available. ${ }^{2,4}$ The definition of IBDU is not merely for academic purposes, as epidemiological data have shown that the clinical course and prognosis of IBDU can be worse than UC, particularly because of the higher rate of pouch failure and long-term complications. ${ }^{2}$

The measurement of serological markers such as anti-Saccharomyces cerevisiae (ASCA) and perinuclear anti-neutrophil cytoplasmic antibodies (pANCA) has been proposed as a method to differentiate CD from UC. Joossens et $\mathrm{al}^{5}$ performed a prospective study to determine whether ASCA or pANCA may be useful in classifying patients with IBDU. Results of this study have demonstrated that serological markers may be helpful in predicting the course of patients with IBDU. However, patients with an initial diagnosis of IBDU and negative serology were more likely to remain indeterminate and it was proposed that these patients may reflect a distinct clinicoserological subgroup of inflammatory bowel disease (IBD).

Capsule endoscopy (CE) has revolutionized the study of the small bowel by providing a reliable method to endoscopically evaluate the entire small bowel. The available data suggest that $\mathrm{CE}$ can identify small-bowel mucosal lesions not observed through other imaging techniques and it may therefore play an important diagnostic role in the evaluation of some patients with known or suspected CD. ${ }^{6}$ Several studies have examined the potential role of $\mathrm{CE}$ in the setting of IBDU/IC, suggesting that $\mathrm{CE}$ is useful in the work-up of these patients by ruling out small-bowel lesions suggestive of $\mathrm{CD}^{6-8}$ Despite these new developments, a 


\begin{tabular}{|c|c|c|c|c|c|c|c|c|c|}
\hline Case & Sex/Age & $\begin{array}{c}\text { Clinical } \\
\text { Presentation }\end{array}$ & $\begin{array}{l}\text { Endoscopic } \\
\text { Features }\end{array}$ & $\begin{array}{l}\text { Pathological } \\
\text { Features }\end{array}$ & $\begin{array}{l}\text { Previous } \\
\text { Therapy }\end{array}$ & $\begin{array}{c}\text { CE } \\
\text { Findings }\end{array}$ & $\begin{array}{c}\text { Final } \\
\text { Diagnosis }\end{array}$ & $\begin{array}{l}\text { Follow-up } \\
\text { (months) }\end{array}$ & $\begin{array}{l}\text { Current } \\
\text { Therapy }\end{array}$ \\
\hline 1 & $\mathrm{M} / 32$ & Nonspecific & Nonspecific & UC like & IS & Group1 & UC & 54 & Surgery \\
\hline 2 & $\mathrm{M} / 45$ & CD like & Nonspecific & UC like & IS & Group1 & IC & 48 & 5ASA \\
\hline 3 & $\mathrm{~F} / 37$ & Nonspecific & UC like & UC like & IS & Group2 & IC & 25 & None \\
\hline 4 & $\mathrm{~F} / 44$ & Nonspecific & Nonspecific & UC like & IS & Group3 & $\mathrm{CD}$ & 24 & $5 \mathrm{ASA}$ \\
\hline
\end{tabular}

IS, immunosuppressive drugs; 5ASA, mesalamine.

long-term follow-up is often the only way to determine the correct diagnosis.

The aim of our study is to evaluate the clinical impact of CE on long-standing IBDU and IC patients with negative serology. We focused on these patients because there is less information available on this subgroup of IBD, for which there is thus a greater need to find an alternative method of diagnosis.

\section{MATERIALS AND METHODS}

\section{Patients}

Eighteen consecutive patients with long-standing IBDU/IC and negative serology were selected. They were included in our study from 2004, undergoing a CE examination, and then followed until the present time (mean follow-up of $31.6 \pm 10.6$ months).

The IBDU group consisted of 14 patients ( 7 females, mean age $40 \pm 12$ years), with a duration of disease of 5.8 \pm 3.3 years (2.5-16 years), whose clinical course did not show correspondence between clinical, endoscopic, and histological features. The IC group consisted of 4 patients ( 2 females, mean age $41 \pm 6$ years) with a duration of disease of $8.9 \pm 5.5$ years (2-10.5 years) for whom a surgical specimen was available.

Data were collected by reviewing the clinical records including age, sex, clinical presentation, endoscopic and pathological features, serological results, and past and current medication. The patients' characteristics are shown in Tables 1 and 2. Seven patients had previously been treated with azathioprine/6-mercaptopurine, cyclosporine, or infliximab (Tables 1, 2).

They showed no evidence of obstructive symptoms and were not taking nonsteroidal antiinflammatory drugs (NSAIDs), aspirin, clopidogrel, or warfarin in the month prior to the examination. None of the CE examinations was conducted during hospitalization or disease exacerbation. A previous examination of the small bowel (standard ileoscopy or radiology) was negative in all cases.

\section{CE Procedure}

A PillCam SB (Given Imaging, Yoqneam, Israel) was used. The patients fasted for 12 hours before the examination. Approximately 10 minutes before ingestion of the capsule $10 \mathrm{mg}$ of metoclopramide was taken orally. The capsule was swallowed with a glass of water containing simethicone. All patients were advised to start drinking water after 2 hours and to have a liquid meal 4 hours after capsule ingestion. After 8 hours the sensor array and the recording device were removed. The digital video image streams of the examinations were downloaded into the RAPID system. The images were then visualized by 2 observers, using the CE structured terminology 9 and were described according to the following classification.

\section{Outcome Measures}

Lesions considered diagnostic of $\mathrm{CD}$ by $\mathrm{CE}$ were 4 or more erosions/ulcers (Fig. 1) and/or the presence of a stricture, and these patients were classified as Group 3. Patients presenting subtle findings such as focal villi denudation (Fig. 2), isolated erosion (Fig. 3), or fewer than 4 erosions/ulcers were considered to belong to Group 2. A normal examination (Fig. 4) was described as Group 1.

We assumed a definitive diagnosis when the disease evolved to the point that a diagnosis of CD or UC was rendered by new data obtained from clinical, laboratory, radiological, endoscopic (including the CE findings), and pathological information.

CD was definitively diagnosed when there was characteristic small-bowel involvement, when fistula occurred, or when granulomas were found at biopsy. ${ }^{1}$ Small-bowel involvement was recognized by the presence of lesions separated by normal mucosa, transmural involvement with fissuring ulcers, and fistula and development of strictures. ${ }^{1}$ Small-bowel lesions were defined as so-called "typical ulcerations" corresponding to excavated lesions (erosions and ulcers) described in the CE structured terminology. ${ }^{9}$ Mow et al $^{13}$ described ulcers as white lesions within a crater and with surrounding erythema, whereas superficial white lesions with surrounding erythema were characterized as erosions. 


\begin{tabular}{|c|c|c|c|c|c|c|c|c|c|}
\hline Case & Sex/ Age & $\begin{array}{c}\text { Clinical } \\
\text { Presentation }\end{array}$ & $\begin{array}{c}\text { Endoscopic } \\
\text { Features }\end{array}$ & $\begin{array}{l}\text { Pathological } \\
\text { Features }\end{array}$ & $\begin{array}{l}\text { Previous } \\
\text { Therapy }\end{array}$ & $\begin{array}{c}\text { CE } \\
\text { Findings }\end{array}$ & $\begin{array}{c}\text { Final } \\
\text { Diagnosis }\end{array}$ & $\begin{array}{c}\text { Follow-up } \\
\text { (months) }\end{array}$ & $\begin{array}{l}\text { Current } \\
\text { Therapy }\end{array}$ \\
\hline 1 & $\mathrm{~F} / 32$ & Nonspecific & CD like & UC like & IS & Group2 & $\mathrm{CD}$ & 31 & $\mathrm{AZT}+\mathrm{IFX}$ \\
\hline 2 & $\mathrm{~F} / 39$ & UC like & CD like & UC like & 5ASA* & Group2 & IBDU & 30 & None \\
\hline 3 & $\mathrm{M} / 48$ & CD like & UC like & UC like & IS & Group2 & IBDU & 31 & IFX \\
\hline 4 & $\mathrm{~F} / 59$ & UC like & UC like & Nonspecific & IS & Group2 & IBDU & 7 & $\mathrm{MTX}+5 \mathrm{ASA}$ \\
\hline 5 & $\mathrm{~F} / 20$ & CD like & Nonspecific & CD like & IS & Group2 & IBDU & 33 & IFX \\
\hline 6 & $\mathrm{M} / 57$ & UC like & Nonspecific & Nonspecific & $5 \mathrm{ASA}^{*}$ & Group2 & IBDU & 26 & 5ASA \\
\hline 7 & $\mathrm{M} / 32$ & CD like & Nonspecific & Nonspecific & 5ASA & Group2 & IBDU & 31 & 5ASA \\
\hline 8 & $\mathrm{~F} / 28$ & UC like & Nonspecific & UC like & IS & Group2 & IBDU & 30 & $\mathrm{AZT}+5 \mathrm{ASA}$ \\
\hline 9 & $\mathrm{~F} / 31$ & UC like & Nonspecific & Nonspecific & $5 \mathrm{ASA}^{*}$ & Group3 & $\mathrm{CD}$ & 31 & Budesonide \\
\hline 10 & $F / 32$ & Nonspecific & CD like & UC like & IS & Group3 & $\mathrm{CD}$ & 31 & $6 \mathrm{MP}+5 \mathrm{ASA}$ \\
\hline 11 & $\mathrm{~F} / 26$ & UC like & UC like & Nonspecific & 5ASA & Group3 & $\mathrm{CD}$ & 31 & $5 \mathrm{ASA}$ \\
\hline 12 & $\mathrm{~F} / 53$ & Nonspecific & Nonspecific & Nonspecific & 5ASA & Group3 & $\mathrm{CD}$ & 48 & 5ASA \\
\hline 13 & $\mathrm{M} / 35$ & Nonspecific & CD like & Nonspecific & 5ASA & Group3 & $\mathrm{CD}$ & 31 & None \\
\hline 14 & $\mathrm{M} / 50$ & UC like & Nonspecific & Nonspecific & 5ASA & Group3 & $\mathrm{CD}$ & 31 & 5ASA \\
\hline
\end{tabular}

*Under mesalamine but needs steroids intermittently for disease control.5ASA, mesalamine; IS, immunosuppressive drugs; 6-MP, 6-mercaptopurine; IFX, infliximab; MTX, methotrexate; AZT, azathioprine.

The definitive diagnosis of UC was based on a surgical specimen with diffuse involvement starting distally and with an absence of transmural inflammation. For cases in which only endoscopic samples were available the diagnosis was based on diffuse colonic inflammation, distally more intense, and normal small-bowel mucosa. ${ }^{1}$

\section{Ethical Considerations}

Informed consent was obtained from all patients. None of the authors have any conflict of interest to report.

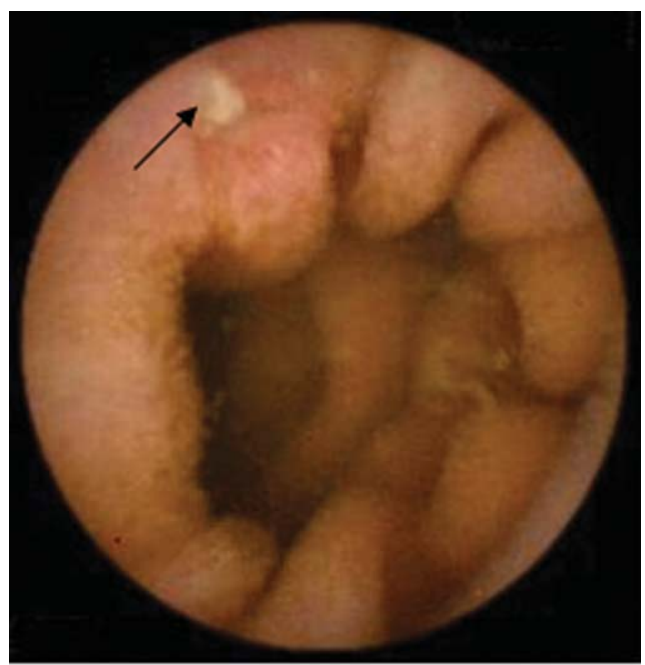

FIGURE 1. Capsule endoscopic diagnostic findings such as an ulcer (described as Group 3). [Color figure can be viewed in the online issue, which is available at wileyonlinelibrary.com.]

\section{RESULTS}

The capsule reached the cecum in all patients. Median gastric transit time and small-bowel transit time were $31.6 \pm 17$ minutes (3-90) and $3.5 \pm 1.6$ hours (1.51$7.47)$, respectively. The procedure was well tolerated and there were no cases of capsule retention or any other adverse event.

The examination was normal in 2 patients (Group 1). Pathological findings detected in the other 16 patients were limited to the mid-small bowel (jejunum and proximal

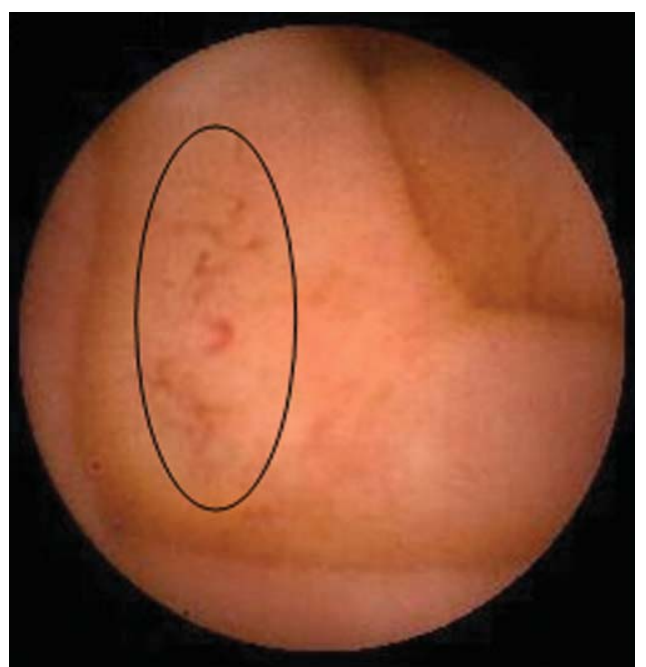

FIGURE 2. Capsule endoscopic subtle findings such as focal villi denudation (described as Group 2). [Color figure can be viewed in the online issue, which is available at wileyonlinelibrary.com.] 


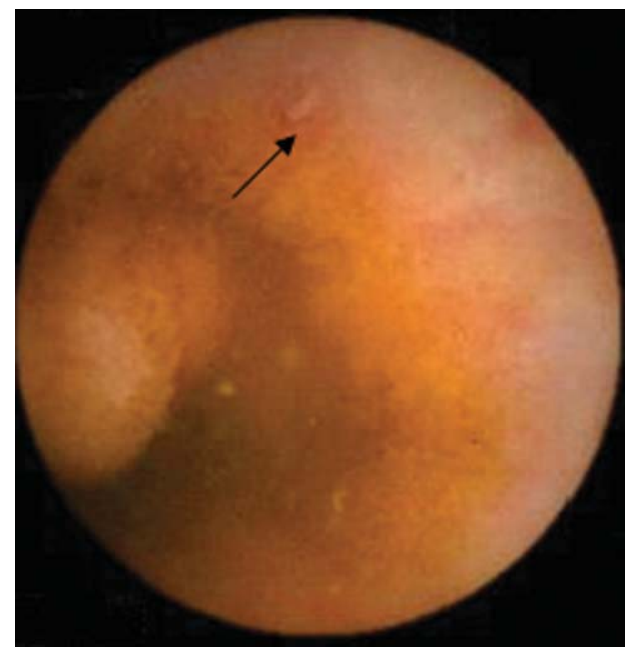

FIGURE 3. Capsule endoscopic subtle findings such as isolated erosion (described as Group 2). [Color figure can be viewed in the online issue, which is available at wileyonlinelibrary.com.]

ileum) in 8 cases, to the distal small-bowel or terminal ileum in 1, and throughout the entire small bowel in 7 cases. In 9 patients subtle findings were observed (Group 2): focal villi denudation in 1 patient, isolated erosion in another patient, and fewer than 4 erosions/ulcers, with a median of 2 lesions, in the remaining 7 patients (Table 3). In 7 patients CE detected significant lesions (Group 3) leading to a $\mathrm{CD}$ diagnosis: 4 ulcers in 1 patient, 6 or more erosions (a median of 8) in 3 patients, and finally, both ulcers and erosions (a median of 7 and 38, respectively) in the remaining 3 patients (Table 3 ). Besides the capsule findings, the clinical strategy was maintained in these last 7 patients: 4 of them are taking mesalamine, 1 is being treated with budesonide, 1 is being kept on 6-mercaptopurine, and the last is asymptomatic without medication.

Despite a nonspecific or a negative CE, a definitive diagnosis was achieved in 2 additional patients after a mean duration of disease of 6 years. CD was diagnosed in 1 case from Group 2, 1 month after $\mathrm{CE}$, in relation to the emergence of a rectovaginal fistula in distal colitis with rectal sparing. This patient was reassessed and started on infliximab infusions. In another case, UC was diagnosed following proctocolectomy performed 1 year after a negative CE in a Group 1 patient who had previously been submitted to a subtotal colectomy to treat a toxic megacolon.

Nine patients remain with a diagnosis of IBDU/IC with a mean disease duration of $9.6 \pm 4$ years (5-17). Of these 9,8 patients are from Group 2 and 1 from Group 1: 3 are taking mesalamine, 2 maintain infliximab infusions, 2 are being kept on azathioprine and methotrexate, respectively, and the last 2 patients are asymptomatic without medication.

\section{DISCUSSION}

$\mathrm{CE}$ can detect mucosal inflammatory changes of the small intestine often missed by other imaging techniques. In a pooled data analysis, $\mathrm{CE}$ had a miss rate for ulcers of only $1 \%{ }^{10}$ Moreover, a meta-analysis comparing CE to other imaging methods to observe the small bowel for IBD has established that $\mathrm{CE}$ has an incremental diagnostic yield of $25 \%-40 \%$ superior to that of other techniques. ${ }^{11}$ On the other hand, published reports on the yield of CE are conditioned by the lack of a validated $\mathrm{CE}$ scoring index that would allow the presence of CD to be predicted. ${ }^{12}$ Mow et $\mathrm{al}^{13}$ used the empirical cutoff of 3 ulcers of any size at CE to establish a diagnosis of $\mathrm{CD}$, but Fidder et $\mathrm{al}^{14}$ defined a positive capsule study for $\mathrm{CD}$ by the presence of 4 or more ulcers, erosions, or a region with clear exudate and mucosal hyperemia and edema. Buchman et $\mathrm{al}^{15}$ graded CE videos as grade 0 (normal), grade 1 (erythema, isolated villi loss), grade 2 (erosion, no ulcer), or grade 3 (ulcers, spontaneous bleeding and/or stricture). Gal et $\mathrm{al}^{16}$ divided the small bowel into 2 on the basis of small-bowel transit time and rated each segment for 3 components: an inflammation score, an extent of disease score, and a narrowing score. More recently, Gralnek et al $^{17}$ created a scoring index based on 3 capsule endoscopic variables: villous appearance, ulcers, and stenosis. The number of lesions was defined as single, few (2-7 lesions), or multiple (8 or more lesions). A score below 135 is classified as normal or clinically insignificant mucosal inflammatory change and a score higher than 790 is classified as moderate to severe.

It must be remembered, however, that there are pathological conditions in which small-bowel permeability is

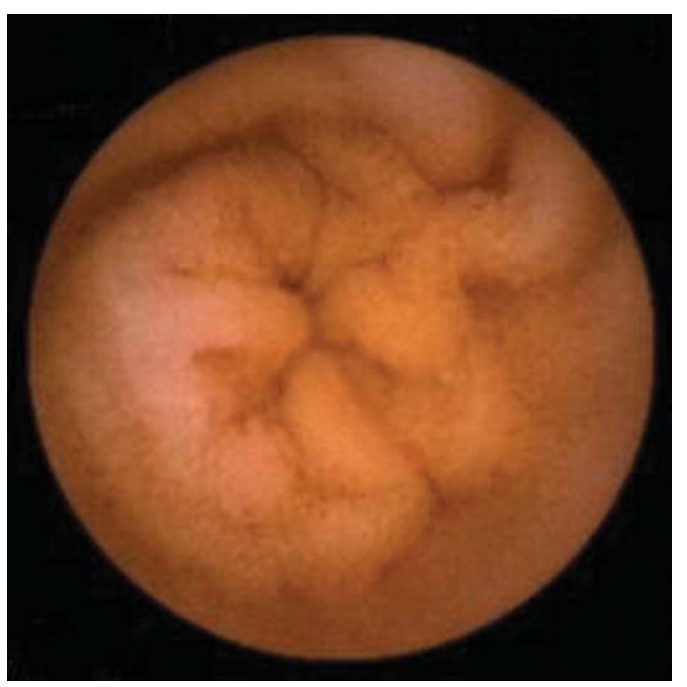

FIGURE 4. Small-bowel mucosa with no alteration (described as Group 1). [Color figure can be viewed in the online issue, which is available at wileyonlinelibrary.com.] 
TABLE 3. CE Findings in the Small Bowel

\begin{tabular}{|c|c|c|c|c|c|c|}
\hline \multirow[b]{2}{*}{ Case } & \multirow[b]{2}{*}{ Sex/ Age } & \multirow[b]{2}{*}{ Initial Diagnosis } & \multicolumn{3}{|c|}{ Capsule Endoscopy Findings } & \multirow[b]{2}{*}{ Final Diagnosis } \\
\hline & & & Group & Type & Location & \\
\hline 1 & $\mathrm{M} / 32$ & IC & Group1 & Normal & 一 & UC \\
\hline 2 & $\mathrm{M} / 45$ & IC & Group1 & Normal & - & IC \\
\hline 3 & $\mathrm{~F} / 37$ & IC & Group2 & Focal villi denudation (FVD) & Mid-small bowel & IC \\
\hline 4 & $\mathrm{~F} / 44$ & IC & Group3 & Erosion $(n=8)$ & Jejunum-ileal & $\mathrm{CD}$ \\
\hline 5 & $\mathrm{~F} / 32$ & IBDU & Group2 & Erosion $(n=1)$ & Mid-small bowel & $\mathrm{CD}$ \\
\hline 6 & $\mathrm{~F} / 39$ & IBDU & Group2 & Erosion $*(n=2)$ & Mid-small bowel & IBDU \\
\hline 7 & $\mathrm{M} / 48$ & IBDU & Group2 & Erosion* $(n=2)$ and FVD & Mid-small bowel & IBDU \\
\hline 8 & $\mathrm{~F} / 59$ & IBDU & Group2 & Erosion $(n=2)$ & Mid-small bowel & IBDU \\
\hline 9 & $\mathrm{~F} / 20$ & IBDU & Group2 & Erosion $*(n=2)$ & Mid-small bowel & IBDU \\
\hline 10 & $\mathrm{M} / 57$ & IBDU & Group2 & Erosion $*(n=3)$ & Mid-small bowel & IBDU \\
\hline 11 & $\mathrm{M} / 32$ & IBDU & Group2 & Erosion* $(n=3)$ and FVD & Jejunum-ileal & IBDU \\
\hline 12 & $\mathrm{~F} / 28$ & IBDU & Group2 & Erosion* $(n=3)$ and FVD & Mid-small bowel & IBDU \\
\hline 13 & $\mathrm{~F} / 31$ & IBDU & Group3 & Ulcer $(n=4)$ & Ileal & $\mathrm{CD}$ \\
\hline 14 & $\mathrm{~F} / 32$ & IBDU & Group3 & Erosion $(n=6)$ & Jejunum-ileal & $\mathrm{CD}$ \\
\hline 15 & $\mathrm{~F} / 26$ & IBDU & Group3 & Erosion* $(n=10)$ & Jejunum-ileal & $\mathrm{CD}$ \\
\hline 16 & $\mathrm{~F} / 53$ & IBDU & Group3 & Erosion $(n=3)$ and Ulcer $(n=10)$ & Jejunum-ileal & $\mathrm{CD}$ \\
\hline 17 & $\mathrm{M} / 35$ & IBDU & Group3 & Erosion $(n=38)$ and Ulcer $(n=2)$ & Jejunum-ileal & $\mathrm{CD}$ \\
\hline 18 & $\mathrm{M} / 50$ & IBDU & Group3 & Erosion $(n=77)$ and Ulcer $(n=7)$ & Jejunum-ileal & $\mathrm{CD}$ \\
\hline
\end{tabular}

*Small erosion.

increased and that all these conditions may have small intestinal erosions and ulcers. They include NSAID intake, lymphoid hyperplasia, lymphoma, radiation enteritis, human immunodeficiency virus with opportunistic infection, intestinal tuberculosis, and Behçet's disease. ${ }^{18}$ Therefore, it is important to exclude all these pathological conditions before a final diagnosis of $\mathrm{CD}$ is made. Until now, none of the above-mentioned conditions has been diagnosed in our patients. On the other hand, Goldstein et $\mathrm{al}^{19}$ reported that $11 \%$ of healthy volunteers had small-intestine mucosal breaks, even in the absence of NSAID intake. Graham et $\mathrm{al}^{20}$ showed that the most severe damage among the nonusers of NSAID controls was 1 small erosion, none of them having 4 or more erosions. These results led us to consider 4 or more erosions/ulcers, or the presence of a stricture, as lesions diagnostic of small-bowel CD. A limitation of our study is the absence of a control group of asymptomatic UC patients to be used as a reference in order to ascertain the baseline frequency of small-bowel lesions in such patients. However, in clinical practice routine evaluation of the small bowel by $\mathrm{CE}$ in asymptomatic patients is not indicated and, therefore, CE may be most clinically useful in a setting in which UC is refractory to medical treatment, or when presenting atypical clinical features, as well as in the case of previous colectomy. ${ }^{21}$ Approximately $10 \%$ of patients with an initial diagnosis of $\mathrm{UC}$ will be reclassified as having either $\mathrm{CD}$ or IBDU at follow-up. ${ }^{21}$ In 1 retrospective study, 19 patients out of $120(16 \%)$, with an established diagnosis of UC and atypical symptoms $(\approx 10 \%)$, or with medically refractory disease $(\approx 9 \%)$, or with prior colectomy for UC and new intestinal complaints $(\approx 33 \%)$, or those with IBDU $(\approx 17 \%)$, could be reclassified as having $\mathrm{CD}$ based on the presence of typical small-bowel ulcerations (defined as the presence of 3 or more ulcerations) seen at $\mathrm{CE}^{8}$

In the setting of IBDU/IC, several studies on the benefit of CE for its evaluation have been published. ${ }^{6-8}$ These small pilot studies found that the use of CE led to a change in the diagnosis of $29 \%-40 \%$ of patients. ${ }^{6}$ A recent multicenter study ${ }^{7}$ looked at 30 seronegative IBDU/IC patients with a mean duration of disease of 6 years (range 1-18). An initial CE was positive in 5 patients, with a mean duration of disease of 4 years (range 1-9), who were later diagnosed with CD. The remaining 25 patients, who had negative capsules, were then followed clinically for 7 years, during which time CE was not repeated. Five more patients were eventually diagnosed as having $\mathrm{CD}$ and 2 as having UC, whereas the diagnosis of the other 18 patients remained indeterminate. Patients with $\mathrm{CD}$ gained a reassessment of their treatment. In the present study, CE enabled the detection of small-bowel lesions diagnostic of CD in 7 patients out of 18 with IC/IBDU (39\%), leading to a definitive diagnosis. We feel confident in the diagnosis of $\mathrm{CD}$ in these patients since, in all cases, CE displayed 
excavated lesions described in the $\mathrm{CE}$ terminology that are usually considered strongly suggestive of $\mathrm{CD} .{ }^{9}$ However, retrospectively, in none of them was the clinical strategy changed by the knowledge of these findings, in contrast with the previous study. This group showed a clinical heterogeneity ranging from asymptomatic with no medication to chronic, continuous illness that requires immunosuppressive drugs for its control.

Although a negative CE has a very high negative predictive value, we cannot exclude a diagnosis of $\mathrm{CD}$. In fact, CE presents false negatives ${ }^{22}$ caused by the miss rate $(\approx 11 \%)$, incomplete examination (in up to $25 \%$ ), technical limitations (battery life duration, field of view), and suboptimal cleanness of the small bowel (in up to $33 \%$ ).

It must also be remembered that capsule examination was not repeated in the present study and these patients (most of them under treatment) may have macroscopic mucosal abnormalities in the small intestine that can heal completely and relapse later. Thus, despite a nonspecific $\mathrm{CE}, 1$ patient in the present series has evolved to a definitive diagnosis of $\mathrm{CD}$ during follow-up management, leading to a change in therapy.

It has often been emphasized that IBDU may be a temporary diagnosis. Joossens et $\mathrm{al}^{5}$ showed that a definitive diagnosis of $\mathrm{CD}$ or $\mathrm{UC}$ within 6 years following disease onset was reached in $32 \%$ of patients. However, 40 $(85 \%)$ of their 47 patients with IBDU and negative serology remained indeterminate at follow-up. In our study, $50 \%$ of patients still have IBDU/IC, further emphasizing the hypothesis that these patients with long-standing "indeterminate" disease and negative serology may belong to an original subgroup of IBD.

These results confirm the ambiguity in relation to the real value of $\mathrm{CE}$ in this heterogeneous IBD group. Thus, larger prospective studies are needed to confirm its usefulness in this setting, as well as to standardize criteria for $\mathrm{CD}$ at $\mathrm{CE}$.

We conclude that, although in patients with longstanding IBDU/IC and negative serology, CE can detect small-bowel lesions which lead to a CD diagnosis in a significant proportion of patients (39\% in our series), this finding did not bring about a modification of the clinical management. Moreover, the single case in which a CD diagnosis ultimately developed, leading to a change in therapy, presented only subtle findings at CE examination. Our results thus suggest that the capsule's findings are not helpful in the clinical management of these patients.

\section{REFERENCES}

1. Lennard-Jones JE. Classification of inflammatory bowel disease. Scand J Gastroenterol Suppl. 1989;170:2-6.
2. Mitchell PJ, Rabau MY, Haboubi NY. Indeterminate colitis. Tech Coloproctol. 2007;11:91-96.

3. Price AB. Overlap in the spectrum of non-specific inflammatory bowel disease - "colitis indeterminate." J Clin Pathol. 1978;31:567-577.

4. Silverberg MS, Satsangi J, Ahmad T, et al. Toward an integrated clinical, molecular and serological classification of inflammatory bowel disease: report of a Working Party of the 2005 Montreal World Congress of Gastroenterology. Can J Gastroenterol. 2005;19(suppl A): $5-36$.

5. Joossens S, Reinisch W, Vermeire S, et al. The value of serologic markers in indeterminate colitis: a prospective follow-up study. Gastroenterology. 2002;122:1242-1247.

6. Leighton JA, Legnani P, Seidman E. Role of capsule endoscopy in inflammatory bowel disease: where we are and where we are going. Inflamm Bowel Dis. 2007;13:331-337.

7. Maunoury V, Savoye G, Bourreille A, et al. Value of wireless capsule endoscopy in patients with indeterminate colitis (inflammatory bowel disease type unclassified). Inflamm Bowel Dis. 2007;13:152-155.

8. Mehdizadeh S, Chen G, Enayati PJ, et al. Diagnostic yield of capsule endoscopy in ulcerative colitis and Inflammatory Bowel Disease of Unclassified type. Endoscopy. 2008;40:30-35.

9. Korman LY, Delvaux M, Gay G, et al. Capsule endoscopy structured terminology (CEST): proposal of a standardized and structured terminology for reporting capsule endoscopy procedures. Endoscopy. 2005; 37:951-959.

10. Lewis B, Eisen G, Friedman S. A pooled analysis to evaluate results of capsule endoscopy trials. Endoscopy. 2005;37:960-965.

11. Triester SL, Leighton JA, Leontiadis GI, et al. A meta-analysis of the yield of capsule endoscopy compared to other diagnostic modalities in patients with non-stricturing small bowel Crohn's disease. Am J Gastroenterol. 2006;101:954-964.

12. Kornbluth A, Colombel JF, Leighton JA, et al. ICCE consensus for inflammatory bowel disease. Endoscopy. 2005;37:1051-1054.

13. Mow WS, Lo SK, Targan SR, et al. Initial experience with wireless capsule enteroscopy in the diagnosis and management of inflammatory bowel disease. Clin Gastroenterol Hepatol. 2004;2:31-40.

14. Fidder HH, Nadler M, Lahat A, et al. The utility of capsule endoscopy in the diagnosis of Crohn's disease based on patient's symptoms. J Clin Gastroenterol. 2007;41:384-387.

15. Buchman AL, Miller FH, Wallin A, et al. Videocapsule endoscopy versus barium contrast studies for the diagnosis of Crohn's disease recurrence involving the small intestine. Am J Gastroenterol. 2004;99: 2171-2177.

16. Gal E, Geller A, Frase G, et al. Assessment of a new simple capsule endoscopy Crohn's disease Activity Index (CECDAI). Gastroenterology. 2006;130:A-477.

17. Gralnek IM, Defranchis R, Seidman E, et al. Development of a capsule endoscopy scoring index for small bowel mucosal inflammatory change. Aliment Pharmacol Ther. 2008;27:146-154.

18. Bar-Meir S. Review article: capsule endoscopy — are all small intestinal lesions Crohn's disease? Aliment Pharmacol Ther. 2006;24(suppl 3):19-21.

19. Goldstein JL, Eisen GM, Lewis B, et al. Video capsule endoscopy to prospectively assess small bowel injury with celecoxib, naproxen plus omeprazole, and placebo. Clin Gastroenterol Hepatol. 2005;3: $133-141$.

20. Graham DY, Opekun AR, Willingham FF, et al. Visible small-intestinal mucosal injury in chronic NSAID users. Clin Gastroenterol Hepatol. 2005;3:55-59.

21. Bourreille A, Ignjatovic A, Aabakken L, et al. Role of small-bowel endoscopy in the management of patients with Inflammatory Bowel Disease: an international OMED-ECCO consensus. Endoscopy. 2009; 41:618-637.

22. Rondonotti E, Villa F, Mulder CJJ, et al. Small bowel capsule endoscopy in 2007: indications, risks and limitations. World J Gastroenterol. 2007;13:6140-6149. 